\section{Amiodarone-induced pulmonary toxicity}

\author{
Junichi Ochi, ${ }^{1}$ Minoru Ohkouchi, ${ }^{1}$ \\ Yoshikazu Tsukada, \\ Shinichiro Tominaga, ${ }^{1}$ Satoshi Takayama, ${ }^{1}$ \\ Yuko Taniguchi, ${ }^{1}$ Yumi Miyamoto, ${ }^{1}$ \\ Naohiko Inase ${ }^{1,2}$ \\ 'Department of Pulmonary Medicine, \\ Yokosuka Kyosai Hospital, Kanagawa, \\ Japan; ' Integrated Pulmonology, Tokyo \\ Medical and Dental University, Tokyo, \\ Japan
}

\section{Abstract}

Amiodarone-induced pulmonary toxicity is a critical and potentially fatal side effect of amiodarone. Our study was designed to reveal its clinical features, including KL-6, as an interstitial marker. The medical records of eight patients (five men and three women) with amiodarone-induced pulmonary toxicity, who had been referred to our hospital, were examined. The mean age at the initiation of amiodarone was 48 years (range, 54-87 years) and mean duration of medication prior to the development of pulmonary toxicity was 18 months (range, 7-33 months). Serum KL-6 was elevated in six of the eight patients with a range of $525-2915 \mathrm{U} / \mathrm{mL}$. Chest computed tomography (CT) findings showed non-segmental consolidation and/or ground glass opacity. Foamy macrophages were found in bronchoalveolar lavage (BAL) fluids of all examined patients and in transbronchial lung biopsy (TBLB) specimens in half of the examined patients. We concluded that serum KL-6, chest CT findings, and foamy macrophages in BAL fluids and TBLB specimens will be helpful for the diagnosis of amiodarone-induced pulmonary toxicity.

\section{Introduction}

Amiodarone is a highly effective antiarrhythmic agent for the treatment of supraventricular and ventricular tachyarrhythmias. ${ }^{1}$ However, there are significant adverse effects associated with amiodarone including bluish discoloration of the skin, photosensitivity, corneal deposits, neurological and muscle disturbances, hyperthyroidism and hypothyroidism, and hepatic and gastrointestinal dysfunction. ${ }^{2-4}$ In addition, amiodarone-induced pulmonary toxicity is a critical and potentially fatal side effect of amiodarone. The incidence of amiodarone-induced pulmonary toxicity varies from $5-15 \%$ with a mortality of 5-10\%. ${ }^{5-13}$

Pulmonary toxicity could be induced by antibiotics, anticancer drugs, anti-inflammatory drugs, anti-arrhythmia drugs, cytokines, herbal medicine, and others. Because newly developed drugs including interferon, gefitinib, leflunomide, and rituximab also have the potential to cause this adverse reaction, physicians have to take care of pulmonary manifestations in every case. Although clinical, radiological, and pathological findings tend to be nonspecific, the precise description of clinical characteristics in each patient with drug-induced pulmonary toxicity seems to be important to differentiate it from other lung diseases. The aim of our study was to describe the clinical features of amiodarone-induced pulmonary toxicity, including KL-6, chest computed tomography (CT) and bronchoalveolar lavage (BAL) findings, as an interstitial marker.

\section{Materials and Methods}

\section{Subjects}

The medical records of eight patients (five men and three women) with amiodaroneinduced pulmonary toxicity, who had been referred to our hospital between 1999 and 2004, were examined. The patients did not have pulmonary fibrosis before amiodarone therapy, and were treated with amiodarone because of ventricular or supraventicular tachyarrhythmia with structural heart disease or heart failure.

\section{Diagnostic criteria}

The diagnostic criteria for amiodaroneinduced pulmonary toxicity include: i) new abnormal findings of chest CT scans; ii) recovery on discontinuation of amiodarone and/or steroid therapy; and iii) no evidence supporting congestive heart failure, infectious diseases, or malignancy.

\section{Results}

The clinical characteristics in the patients who received amiodarone therapy are summarized in Table 1 . The mean age at the initiation of amiodarone therapy was 48 years (range, 54-87 years). Amiodarone was administrated because of ventricular tachycardia, ventricular fibrillation, and atrial fibrillation. The patients had been receiving the medication for 7-33 months prior to having amiodarone-induced pulmonary toxicity. The dose of amiodarone was $400 \mathrm{mg}$ daily $(\mathrm{n}=1), 200 \mathrm{mg}$ daily $(n=4)$, and $100 \mathrm{mg}$ daily $(n=3)$. The patient (\#6) who had been receiving $400 \mathrm{mg}$ of
Correspondence: Naohiko Inase, Integrated Pulmonology, Tokyo Medical and Dental University, 1-5-45, Yushima, Bunkyo-ku, Tokyo, 113-8519, Japan.

Tel. 81.3.5803.5950 - Fax: 81.3.5803.0167.

E-mail: ninase.pulm@tmd.ac.jp

Key words: amiodarone, pulmonary toxicity, KL-6, foamy macrophage.

Contributions: this study was designed by J0 and NI; clinical data was collected by MO, YTs, STo, STa, YTa, and YM; and the manuscript was critically prepared by NI.

Conflict of interest: the authors report no conflicts of interest.

Received for publication: 2 March 2011. Accepted for publication: 24 May 2011.

This work is licensed under a Creative Commons Attribution NonCommercial 3.0 License (CC BYNC 3.0 ).

CC Copyright J. Ochi et al., 2011

Licensee PAGEPress, Italy

Chest Disease Reports 2011; 1:e6

doi:10.4081/cdr.2011.e6

amidarone daily was treated with $200 \mathrm{mg}$ daily four months later. Four patients were treated with steroids as well as by discontinuation of amiodarone. Clinically, the symptoms of every patient disappeared within a few weeks. Serum KL-6 was elevated in six of the eight patients, with a range of 525-2915 U/mL (Table 1). Chest CT scans showed pulmonary changes including non-segmental consolidation $(\mathrm{n}=7$, $88 \%)$, consolidation around the bronchus $(\mathrm{n}=5,63 \%)$, ground glass opacity (GG0; $\mathrm{n}=4$, $50 \%$ ), thickening of the bronchovascular bundle $(\mathrm{n}=2,25 \%)$, and interlobular septal thickening ( $n=1,13 \%)$ (Figure 1). Honeycombing could not be demonstrated. A surgical lung biopsy was performed in one patient, which revealed parenchymal changes of a nonspecific interstitial pneumonia pattern, with foamy macrophages in the alveolar septa as well as the alveolar spaces (Figure 2). Four of the eight patients underwent bronchoscopy to perform BAL and a transbronchial lung biopsy (TBLB). In BAL fluids, foamy macrophages were found and the CD4/CD8/T-lymphocytes ratio was lowered in all examined patients (Table 2). In TBLB specimens, foamy macrophages could be detected in two of four patients.

\section{Discussion}

Amiodarone-induced pulmonary toxicity is clinically complex and likely reflects underlying mechanisms of lung injury that result from 
direct toxic effects of the drug (or its metabolites) and indirect inflammatory and immunologic processes. ${ }^{9}$ In BAL fluids, cytotoxic T-cells can be found, often in combination with polymorphonuclear cells. ${ }^{8}$ Amiodarone inhibits phospholipase A, which can induce an accumulation of phospholipids within lysosomes in the lungs and other tissues. Lipid-laden foamy macrophages are seen commonly during histological examinations. Martin et al. reported that the presence of foamy macrophages in biopsy specimens could also be detected in up to one half of nontoxic patients receiving amiodarone. ${ }^{8}$ Therefore, detection of foamy macrophages in BAL fluids does not reliably distinguish toxic from nontoxic patients. However, foamy macrophages would be a supportive finding in the diagnosis of amiodarone-induced pulmonary toxicity, as shown in the BAL fluids of all examined patients in our study.

Although the risk of developing side effects rises with the plasma concentration of amiodarone, ${ }^{14}$ there is no concentration at which pulmonary toxicity can be predicted. Some studies indicated that the toxic effect was related to a daily dose of amiodarone. ${ }^{15-17}$ However, Ott et al. showed that low-dose amiodarone $(200 \mathrm{mg} /$ day) could increase the risk for pulmonary toxicity, ${ }^{18}$ which is consistent with the results in our study. The risk of amiodarone-induced pulmonary toxicity correlates better with the total cumulative dose than with the daily dose and plasma concentrations. ${ }^{16,19,20}$ Because of its lipophilic nature, amiodarone tends to accumulate in adipose, liver, and lung tissues. ${ }^{6}$ The terminal elimination half-life is extremely long, averaging 52 days. ${ }^{21}$ Even when amiodarone is discontinued, the toxic effect may persist because of the long half-life. Corticosteroids should be given for months and tapered prudently to avoid a relapse. ${ }^{22}$

KL-6 is a high-molecular weight, mucin-like glycoprotein and has been reported as a marker for interstitial lung diseases including idiopathic interstitial pneumonias, collagen vascular disease-associated interstitial pneumonia, hypersensitivity pneumonitis, and druginduced pneumonitis. ${ }^{23,24}$ In some previous studies of amiodarone-induced pulmonary toxicity, an increase in serum KL-6 has been described. ${ }^{25,26}$ In our study, six of the eight patients showed an elevated serum KL-6 level, which might be helpful for the detection of pulmonary toxicity during amiodarone therapy, although its sensitivity was not high enough.

Reported pulmonary toxicities range from mild subacute illness to rapidly progressive and fatal adult respiratory distress syndrome. Vernhet et al. showed that GGO, intralobular reticulations, subpleural consolidations, and bronchial abnormalities including dilation and wall thickening were common chest CT findings in reversible amiodarone-induced pul-

Table 1. Clinical characteristics.

\begin{tabular}{|c|c|c|c|c|c|c|c|}
\hline No. & Gender & Age & $\begin{array}{l}\text { Primary } \\
\text { diseases }\end{array}$ & $\begin{array}{l}\text { Duration of } \\
\text { therapy } \\
\text { (months) }\end{array}$ & $\begin{array}{l}\text { Dose of } \\
\text { amiodarone } \\
\text { (mg/day) }\end{array}$ & Symptoms & $\begin{array}{c}\mathrm{KL}-6 \\
(\mathrm{U} / \mathrm{mL})\end{array}$ \\
\hline 1 & Male & 87 & $\begin{array}{c}\text { Paf, VPC } \\
\text { OMI }\end{array}$ & 7 & 100 & Cough & 525 \\
\hline 2 & Female & 59 & af, MS & 26 & 200 & DOE & 2915 \\
\hline 3 & Male & 79 & VT, AMI & 12 & 200 & None & 544 \\
\hline 4 & Female & 56 & af & 12 & 200 & Cough & 1750 \\
\hline 5 & Male & 58 & $\begin{array}{c}\text { VF, APC } \\
\text { IHD }\end{array}$ & 33 & 200 & $\begin{array}{c}\text { DOE } \\
\text { hemoptysis }\end{array}$ & 263 \\
\hline 6 & Female & 54 & $\begin{array}{c}\text { Paf } \\
\text { HOCM }\end{array}$ & 12 & $400 \rightarrow 200$ & Cough & 370 \\
\hline 7 & Male & 77 & $\mathrm{Paf}$ & 24 & 100 & None & 703 \\
\hline 8 & Male & 67 & VT & 22 & 100 & None & 624 \\
\hline
\end{tabular}

Paf, paroxysmal atrial fibrillation; $\mathrm{VPC}$, ventricular premature contraction; OMI, old myocardial infarction; af, atrial fibrillation; $\mathrm{MS}$, mitral valve stenosis; VT, ventricular tachycardia; AMI, acute myocardial infarction; VF, ventricular fibrillation; $\mathrm{APC}$, atrial premature contraction; IHD, ischemic heart disease; HOCM, hypertrophic obstructive cardiomyopathy; DOE, dyspnea on effort.

Table 2. Bronchoalveolar lavage findings.

\begin{tabular}{ccccccc} 
No. Total cells & $\begin{array}{c}\text { Macrophages* } \\
(\text { \% }\end{array}$ & $\begin{array}{c}\text { Lymphocytes } \\
(\%)\end{array}$ & $\begin{array}{c}\text { Neutrophils } \\
(\%)\end{array}$ & $\begin{array}{c}\text { Eosinophils } \\
(\%)\end{array}$ & CD4/CD8 \\
\hline 1 & $1.1 \times 10^{5}$ & 93 & 4 & 2 & 1 & 0.34 \\
2 & $3.4 \times 10^{5}$ & 65 & 10 & 0 & 25 & 0.13 \\
\hline 5 & $13.1 \times 10^{5}$ & 95 & 5 & 0 & 0 & 0.25 \\
6 & $2.0 \times 10^{5}$ & 9 & 86 & 3 & 2 & 0.81 \\
\hline
\end{tabular}

* Foamy macrophages were found in all four patients.

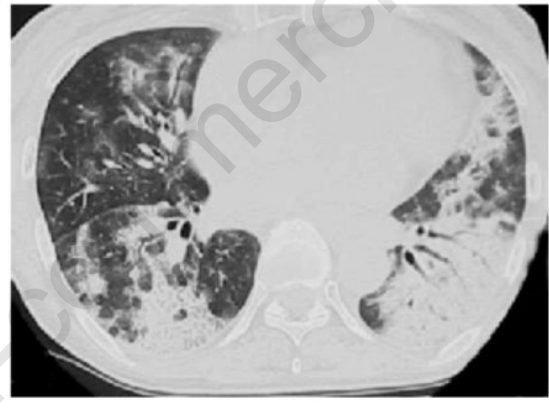

Figure 1. Chest computer tomography scan in patient \#2 showing consolidations around the bronchus and non-segmental consolidations as well as ground glass opacities.

monary toxicity. ${ }^{27}$ There was no report of honeycombing in amiodarone-induced pulmonary toxicity. In our study, the most common chest CT findings were bilateral non-segmental consolidation and GGO. After therapeutic management, all patients showed improvement of radiological findings, suggesting that most pulmonary signs and symptoms were reversible. We concluded that serum KL-6, chest CT findings, and foamy macrophages in BAL fluids and TBLB specimens will be helpful for the diagnosis of amiodarone-induced pulmonary toxicity.

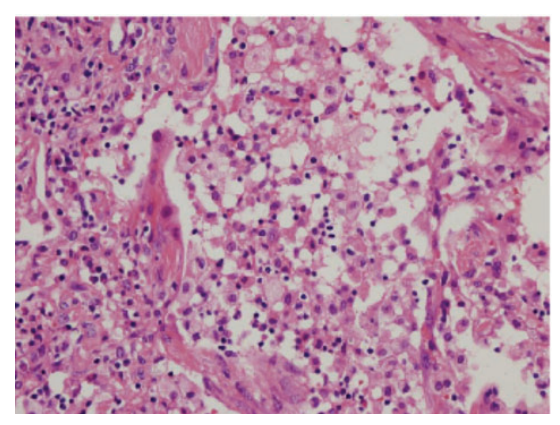

Figure 2. Surgical lung biopsy specimen in patient \#4 showing interstitial pneumonia with intra-alveolar foamy macrophages (hematoxylin-eosin stain).

\section{References}

1. Amiodarone Trials Meta-Analysis Investigators. Effect of prophylactic amiodarone on mortality after acute myocardial infarction and in congestive heart failure: meta-analysis of individual data from 6500 patients in randomised trials. Lancet 1997;350:1417-24.

2. Harris L, McKenna WJ, Rowland E, et al. Side effects of long-term amiodarone therapy. Circulation 1983;67:45-51.

3. Greene HL, Graham EL, Werner JA, et al. Toxic and therapeutic effects of amio- 
darone in the treatment of cardiac arrhythmias. J Am Coll Cardiol 1983;2:1114-28.

4. Smith WM, Lubbe WF, Whitlock RM, et al. Long-term tolerance of amiodarone treatment for cardiac arrythmias. Am J Cardiol 1986;57:1288-93.

5. Wilson BD, Clarkson CE, Lippmann ML. Amiodarone-induced pulmonary inflammation. Correlation with drug dose and lung levels of drug, metabolite, and phospholipid. Am Rev Respir Dis 1991;143: 1110-4.

6. Mason JW. Amiodarone. N Engl J Med 1987;316:455-66.

7. Dusman RE, Stanton MS, Miles WM, et al. Clinical features of amiodarone-induced pulmonary toxicity. Circulation 1990; 82:51-9.

8. Martin WJ II, Rosenow EC III. Amiodarone pulmonary toxicity. Recognition and pathogenesis (part I). Chest 1988a; 93:1067-75.

9. Martin WJ II, Rosenow EC III. Amiodarone pulmonary toxicity. Recognition and pathogenesis (part II). Chest 1988b;93: 1242-8.

10. Pitcher WD. Amiodarone pulmonary toxicity. Am J Med Sci 1992;303:206-12.

11. Ernawati DK, Stafford L, Hughes JD. Amiodarone-induced pulmonary toxicity. Br J Clin Pharmacol 2008;66:82-7.

12. Papiris SA, Triantafillidou C, Kalilekas L,
Markoulaki D, Manali ED. Amiodarone: review of pulmonary effects and toxicity. Drug Saf 2010;33:539-58.

13. Nikaido A, Tada T, Nakamura K, et al. Clinical features of and effects of angiotensin system antagonists on amiodarone-induced pulmonary toxicity. Int J Cardiol 2010;140:328-35.

14. Martin WJ II, Howerd DM. Amiodaroneinduced pulmonary toxicity: in vitro evidence for the direct toxicity of the drug. Am J Pathol 1985;120:344-50.

15. Rotmensch HH, Belhassen B, Swanson BN, et al. Steady-state serum amiodarone concentrations: relationship with antiarrythmic efficacy and toxicity. Ann Intern Med 1984;101:462-9.

16. Rakita L, Sobol SM, Mostow N, Vrobel T. Amiodarone pulmonary toxicity. Am Heart J 1983;106:906-16.

17. Olson LK, Forrest JV, Friedman PJ, Kiser PE, Henschke CI. Pneumonitis after amiodarone therapy. Radiology 1984;150:32730.

18. Ott MC, Khoor A, Leventhal JP, Paterick TE, Burger CD. Pulmonary toxicity in patients receiving low-dose amiodarone. Chest 2003;123:646-51.

19. Liu FL, Cohen RD, Downar E, et al. Amiodarone pulmonary toxicity: functional and ultrastructural evaluation. Thorax 1986;41:100-5.
20. Kudenchuk PJ, Pierson DJ, Greene HL, et al. Prospective evaluation of amiodarone pulmonary toxicity. Chest 1984;86:541-8.

21. Holt DW, Tucker GT, Jackson PR, Storey GCA. Amiodarone pharmacokinetics. Am Heart J 1983;106:840-7.

22. Camus P, Bonniaud P, Fanton A, et al. Drug-induced and iatrogenic infiltrative lung disease. Clin Chest Med 2004;25:479519.

23. Kohno N, Kyoizumi S, Awaya Y, et al. New serum indicator of interstitial pneumonitis activity: sialylated carbohydrate antigen KL-6. Chest 1989;96:68-73.

24. Ohnishi H, Yokoyama A, Yasuhara Y, et al. Circulating KL-6 levels in patients with drug induced pneumonitis. Thorax 2003; 58:872-5.

25. Endoh Y, Hanai R, Uto K, et al. Diagnostic accuracy of KL-6 as a marker of amiodarone-induced pulmonary toxicity. Pacing Clin Electrophysiol 2000;23:2010-3.

26. Yamada Y, Shiga T, Matsuda N, Hagiwara $\mathrm{N}$, Kasanuki $\mathrm{H}$. Incidence and predictors of pulmonary toxicity in Japanese patients receiving low-dose amiodarone. Circ J 2007;71:1610-6.

27. Vernhet H, Bousquet C, Durand G, Giron J, Senac JP. Reversible amiodarone-induced lung disease: HRCT findings. Eur Radiol 2001;11:1697-703. 